OPEN ACCESS

Edited by:

Marco Catoni,

University of Birmingham,

United Kingdom

Reviewed by:

Javier Plasencia,

National Autonomous University of

Mexico, Mexico

John Laurie

Agriculture and Agri-Food Canada,

Canada

Alessandra Lanubile,

Catholic University of Sacred Heart,

Italy

*Correspondence:

Elżbieta Czembor e.czembor@ihar.edu.pl

Specialty section:

This article was submitted to

Plant Microbe Interactions,

a section of the journal

Frontiers in Microbiology

Received: 17 October 2018

Accepted: 20 February 2019

Published: 18 March 2019

Citation:

Czembor E, Waśkiewicz A,

Piechota U, Puchta M, Czembor JH and Stẹpień $Ł$ (2019) Differences in

Ear Rot Resistance and Fusarium verticillioides-Produced Fumonisin

Contamination Between Polish

Currently and Historically Used Maize

Inbred Lines. Front. Microbiol. 10:449.

doi: 10.3389/fmicb.2019.00449

\section{Differences in Ear Rot Resistance and Fusarium verticillioides-Produced Fumonisin Contamination Between Polish Currently and Historically Used Maize Inbred Lines}

\author{
Elżbieta Czembor ${ }^{1 *}$, Agnieszka Waśkiewicz ${ }^{2}$, Urszula Piechota ${ }^{3}$, Marta Puchta $^{3}$, \\ Jerzy H. Czembor ${ }^{3}$ and Łukasz Stẹpień ${ }^{4}$
}

\footnotetext{
${ }^{1}$ Department of Grasses, Legumes and Energy Plants, Plant Breeding and Acclimatization Institute - NRI, Radzikow, Blonie, Poland, ${ }^{2}$ Department of Chemistry, Poznań University of Life Sciences, Poznań, Poland, ${ }^{3}$ National Centre for Genetic Resources, Plant Breeding and Acclimatization Institute - NRI, Radzikow, Blonie, Poland, ${ }^{4}$ Department of Pathogen Genetics and Plant Resistance, Institute of Plant Genetics, Polish Academy of Sciences, Poznań, Poland
}

Poland is the fifth largest European country, in terms of maize production. Ear rots caused by Fusarium spp. are significant diseases affecting yield and causing grain mycotoxin contamination. Inbred lines, which are commonly used in Polish breeding programs, belong, mostly, to two distinct genetic categories: flint and dent. However, historically used lines belonging to the heterotic Lancaster, IDT and SSS groups were also present in previous Polish breeding programs. In the current study, 98 inbred lines were evaluated across a 2-year-long experiment, after inoculation with $F$. verticillioides and under natural infection conditions. Lancaster, IDT, SSS and SSS/IDT groups were characterized as the most susceptible ones and flint as the more resistant. Based on the results obtained, the moderately resistant and most susceptible genotypes were defined to determine the content of fumonisins (FBs) in kernel and cob fractions using the HPLC method. Fumonisin's content was higher in the grain samples collected from inoculated plants than in cobs. The association of visible Fusarium symptoms with fumonisin concentration in grain samples was significant. Conversely, the cobs contained more $\mathrm{FB}_{1}$ under natural infection, which may be related to a pathogen's type of growth, infection time or presence of competitive species. Using ddRADseq genome sampling method it was possible to distinguish a basal relationship between moderately resistant and susceptible genotypes. Genetic distance between maize genotypes was high. Moderately resistant inbreed lines, which belong to IDT and IDT/SSS belong to one haplotype. Genotypes which belong to the flint, dent or Lancaster group, and were characterized as moderately resistant were classified separately as the same susceptible one. This research has demonstrated that currently grown Polish inbred lines, as well the ones used in the past are a valid source of resistance to Fusarium ear rot. A strong association was observed between 
visible Fusarium symptoms with fumonisin concentration in grain samples, suggesting that selection in maize for reduced visible molds should reduce the risk of mycotoxin contamination. NGS techniques provide new tools for overcoming the long selection process and increase the breeding efficiency.

Keywords: maize inbred lines, Fusarium ear rot, fumonisin accumulation, genetic distance assessment, ddRADseq

\section{INTRODUCTION}

Maize has become one of the most important crops for food and feed production worldwide-both as silage and crop residue. It is also used industrially for starch and oil extraction. The production area in Poland has reached 1200 thousand ha. Fungal diseases are among the most important factors limiting the yield and grain quality of maize, with Fusarium ear rots (FER) caused by Fusarium at the top of the list. Fusaria has the ability to produce toxins which are harmful to both humans and animals alike. The environment has a huge impact on these processes and this is also being studied. In Europe the most common ear rotting fungal species are: F. verticillioides (Sacc.) Nirenberg, causing pink ear rot, and F. graminearium Schwabe, causing red ear rot. However, a number of minor species are also present: F. temperatum, F. poae, F. proliferatum, F. avenaceum, F. culmorum F. subglutinans, and F. sporotrichioides. Maize grain is mostly contaminated with fumonisins produced by $F$. verticillioides and $F$. proliferatum, and/or by deoxynivalenol and other trichothecenes along with zearalenone produced by $F$. graminearum, which affect the health of human and animals (Desjardins and Plattner, 2000; Logrieco et al., 2002; Bennett and Klich, 2003; Munkvold, 2003b; Oldenburg and Ellner, 2005; Voss et al., 2006; Dorn et al., 2009; Czembor et al., 2014, 2015; Gallo et al., 2015; Stoycho, 2015; Miedaner et al., 2017). The maximum acceptable levels of mycotoxin content have been established for both maize and maize products. The guidance has been placed for foodstuffs (EC, 2007) and for animal feed in the European Union (EC, 2006). Contamination of maize grain or feed product is influenced by environmental conditions, agricultural practices, genotype resistance and the interaction between all of these factors (Maiorano et al., 2009a,b; Vasileiadis et al., 2011; Zijlstra et al., 2011; Mesterhazy et al., 2012; Cao et al., 2014b; Miedaner et al., 2017). Fusarium verticillioides can cause disease, at all developmental stages of the plant, in some cases without displaying any symptoms and, consequently, fumonisins are present in symptomless infected kernels (Desjardins and Plattner, 2000; Desjardins et al., 2002; Miedaner et al., 2010).

Ear rot caused by $F$. verticillioides favored warm and dry conditions, however, warm and wet conditions following silking have been reported to be conducive for disease development (Munkvold, 2003b). Weather conditions during flowering are critical for primary infection, as well as for toxin accumulation during flowering and then before harvesting (De La Campa et al., 2005; Maiorano et al., 2009a,b; Cao et al., 2014b). Low rainfall and a high number of days with maximum temperatures around $30-35^{\circ} \mathrm{C}$ during flowering favor disease development. Additionally, precipitation stimulates mycotoxin accumulation before the maturity stage because of the extended harvest period.

Appropriate agronomic practice is one of the most effective approaches to reduce mycotoxin contamination of maize grain (Munkvold, 2003a; Ariño et al., 2009; Mesterhazy et al., 2012; de Galarreta et al., 2015) along with the use of less susceptible hybrids, which can be developed either by traditional breeding methods or by transgenic technology (Munkvold, 2003a; Smith et al., 2004; Presello et al., 2005, 2011; Butrón et al., 2006; Smith, 2007; Toldi et al., 2008; Eller et al., 2010; Lanubile et al., 2011; Mesterhazy et al., 2012; Czembor et al., 2015). Genetic resistance is needed in currently used cultivars and it can be deployed from available intra-specific variability. The understanding of the mechanisms underlying maize resistance to ear rot is still limited. Their nature is polygenic and mapped resistance quantitative trait loci (QTL) have relatively small effects and are not consistent between populations (Pérez-Brito et al., 2001; Robertson-Hoyt et al., 2006; Ding et al., 2008; Xiang et al., 2010; Ali and Yan, 2012; Chen et al., 2012; Yuan et al., 2013; Zila et al., 2013, 2014; Mideros et al., 2014; Butrón et al., 2015; Lanubile et al., 2017). The accumulation of mycotoxins can also be affected by the plant genotype. Pedigree breeding has caused maize inbreeds to become not only more-elite but also genetically more uniform. Older generations of inbred lines are still used in inbred line development and genetic studies or as testers in many breeding programs (Presello et al., 2005, 2011; Mesterhazy et al., 2012). The most utilized inbreds belong into the heterotic groups such as Reid Yellow Dent, Iowa Stiff Stalk Synthetic (SSS), Lancaster, Iodent (IDT) and have not been subjected to phenotypic selection for FER resistance. Flint and popcorn hybrids tend to exhibit less FER severity and grain mycotoxin contamination than dent ones, though resistant dent hybrids are also available (Presello et al., 2007). The stability of the earlier germplasms from Argentina was evaluated in Argentinian and Canadian environments (Presello et al., 2004, 2005, 2011). German conditions were evaluated by Bolduan et al. (2009) and Löffler et al. (2010) who concluded that the sources of resistance are effective in different locations. South African conditions were evaluated by Small et al. (2012), Italian by Balconi et al. (2014) Central European (Poland) by Czembor and Frasinski (2018) and Czembor et al. (2013a,b, 2015).

The breeding programs intensified the development of more resistant genotypes and the identification of new resistance sources, the plant selection procedures and QTL mapping. The resistance mechanism is also being studied. Recently, next-generation sequencing (NGS) technology has emerged as a cutting-edge approach for high-throughput sequence determination. It has improved the efficiency and speed of gene discovery, reducing the time, labor, and cost (Robertson et al., 
2006; Elshire et al., 2011; Mesterhazy et al., 2012; Peterson et al., 2012; Zila et al., 2014).

In summary the objectives of this study were: (i) to evaluate the variation of FER resistance and mycotoxin contamination caused by $F$. verticilliides among a broad base of early, midearly and late groups of maize elite inbred lines belonging to currently used flint and dent groups as well as historical heterotic groups such as Lancaster, IDT, SSS, and (ii) to estimate the level of genetic diversity among and within these groups using NGS technology. Inbreds possessing resistance to FER and fumonisin accumulation would be valuable materials for future breeding programs.

\section{MATERIALS AND METHODS}

\section{Plant Materials}

Ninety-eight inbred lines were evaluated, belonging to currently used flint $(n=23)$ and dent $(n=39)$ inbred groups, as well as historically used heterotic groups such as Lancaster $(n=4)$, Iodent Reid (IDT, $n=9$ ), Stiff Stalk Synthetic (SSS, $n=8$ ) and SSS/IDT (S/I, $n=5$ ).A heterotic group of 10 lines was unknown. Based on phenotypic FER assessment, genotypes were divided into 4 groups: highly resistant, moderately resistant, moderately susceptible and very susceptible. Moderately resistant and very susceptible genotypes, representing each heterotic group (30 inbreds: 10 dents, 8 flints, 3 IDT, 2 Lancaster, 3 SSS, 2 SSS/IDT, 2 of the unknown heterotic group), were selected for further research aimed at determining the content of fumonisins in grain and cob fractions (Figure 1).

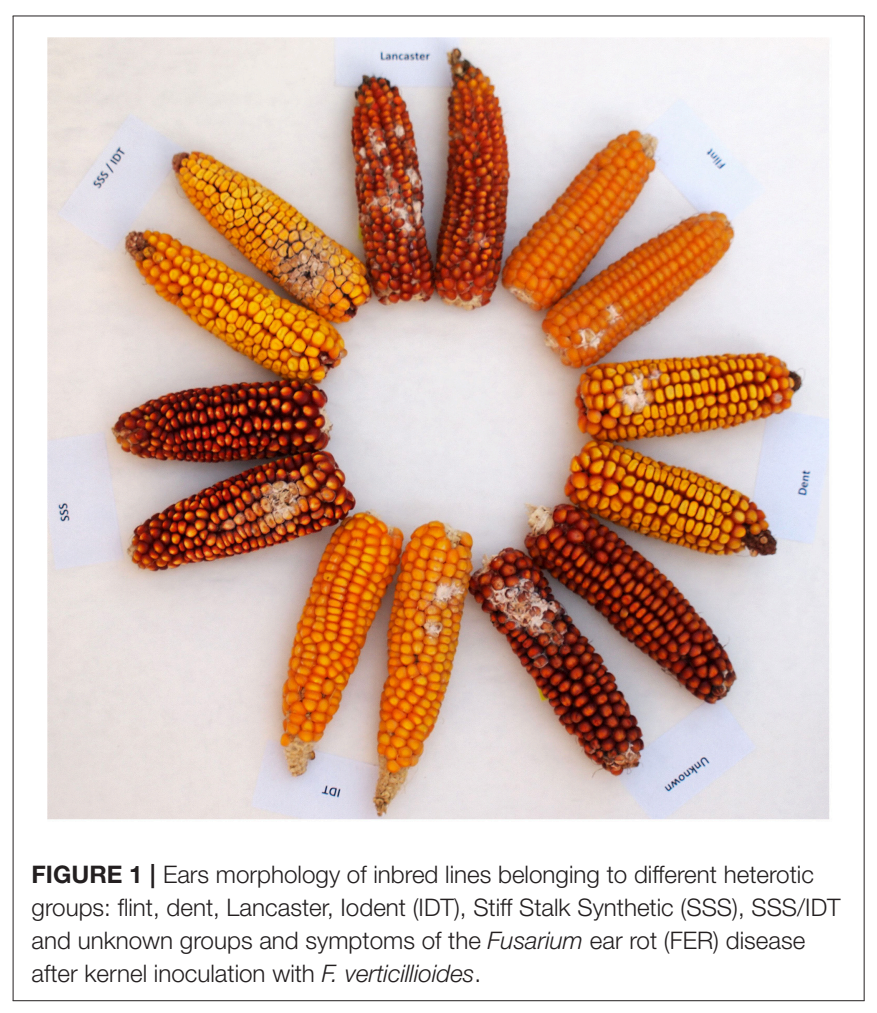

\section{Field Experiment and Phenotypic Ear Rot Resistance Assessment}

Two-year field experiments were conducted in Radzików, Central Poland (N: 52.21929, 20.63137, sea level: $87 \mathrm{~m}$ ), across 2011-2012 seasons, as was suggested by Bolduan et al. (2009). They recommended a two-stage selection: an online personal contribution by artificial infection at one place and the next between test hybrids in several (2-3) locations. An RCBD (randomized complete block design) model was used for the field experiment. About 25 plants of maize inbred lines were grown in one row, in three replications $(0.75 \mathrm{~m}$ between rows and $0.25 \mathrm{~m}$ between plants in the row).

To produce inoculum, a well-characterized fumonisinproducing $F$. verticillioides strain was used. This isolate was selected from the collection carried out by Plant Breeding and Acclimatization Institute-NRI based on the results of a 2-year experiment as the most aggressive in relation to two hybrids of maize. A PDA (Potato dextrose agar) plug with 7 day-old culture was transferred to a $10-\mathrm{mL}$ vial containing 12 autoclaved toothpicks and 8-mL SNA (Synthetic low-Nutrient Agar) and incubated for 2 weeks at $25^{\circ} \mathrm{C}$. Prior to autoclaving, the toothpicks were washed and boiled in excess water for $1 \mathrm{~h}$ to remove any toxic substances that might inhibit fungal growth (Jardine and Leslie, 1992). After incubation the toothpicks were removed from the vials and air-dried on a sterile bench overnight.

Inoculation of individual ears was conducted 10-12 days after silking time. At least 20 plants were inoculated for each genotype (6-7 plants in three replicates). Control plants were inoculated using toothpicks without the pathogen. At maturity, ears from each plot were dehusked and harvested manually, dried to approximately $15 \%$ grain moisture content and individually rated for FER symptoms using a seven-point scale: $1=$ no visible disease symptoms, $2=1-3 \%, 3=4-10 \%, 4=11-$ $25 \%, 5=26-50 \%, 6=51-75 \%$, and $7=76-100 \%$ of kernels exhibiting visual symptoms of infection, such as brown, pink, or reddish discoloration of kernels and pinkish or white mycelial growth (Clements et al., 2003a,b; Supplementary Figure 1). Ear rot severity scores were converted to percentages of the ear exhibiting symptoms replacing each score with the mid-point of the interval.

\section{Fumonisins Analysis}

Fumonisin $\mathrm{B}_{1}, \mathrm{~B}_{2}, \mathrm{~B}_{3}$ standards were purchased with a standard grade certificate from Sigma-Aldrich (Steinheim, Germany). Sodium dihydrophosphate, potassium chloride, acetic acid and $o$-phosphoric acid were purchased from POCh (Gliwice, Poland). Organic solvents (HPLC grade), disodium tetraborate, 2mercaptoethanol and all the other chemicals were also purchased from Sigma-Aldrich (Steinheim, Germany). Water for the HPLC mobile phase was purified using a Milli-Q system (Millipore, Bedford, MA, USA).

Extraction and purification procedure: $10 \mathrm{~g}$ of homogenized ground samples of maize kernels were prepared for analysis. Mycotoxins (FBs) were extracted and purified according to the detailed procedure described earlier (Waśkiewicz et al., $2013 \mathrm{a}, \mathrm{b})$. The eluates were evaporated to dryness at $40^{\circ} \mathrm{C}$ under a 
stream of nitrogen. The dry residue was stored at $-20^{\circ} \mathrm{C}$ until the HPLC analyses. The chromatographic system consisted of Waters 2695 high-performance liquid chromatography (Waters, Milford, USA) with Waters 2475 Multi $\lambda$ Fluorescence Detector $(\lambda$ ex $=335 \mathrm{~nm}, \lambda \mathrm{em}=440 \mathrm{~nm})$ with an XBridge column $(3.0 \times$ $100 \mathrm{~mm}$ ). Quantification of mycotoxins was performed by measuring the peak areas at the retention time according to a relevant calibration curve. The limit of detection was $0.01 \mu \mathrm{gg}^{-1}$.

\section{Genetic Distance Assessment}

The level of genetic diversity among 17 distinct maize genotypes was analyzed using NGS technology. They were selected as moderately resistant and susceptible to ear rot, based on the evaluation under field conditions after inoculation and fumonisin content.

For different combinations of restriction enzymes, it is possible to perform sequencing from 0.01 to $1.99 \%$ of maize genome size due to the ddRAD in silico pipeline (Yang et al., 2016). That fraction selected by the ddRADseq pipeline is enough for a broad spectrum of research. The ddRADseq method is used in phylogeny analysis and establishing a genetic relationship among different genotypes. Different restriction enzymes and broad or narrow size selection make the library proper to MiSeq capacity. DdRADseq does not need a reference sequence (Peterson et al., 2012).

Genomic DNA was extracted from $200 \mathrm{mg}$ of 14-day-old single plant leaf tissue by CTAB method (Waśkiewicz et al., 2013 b) with RNase A (Qiagen) treatment before precipitation $\left(30 \mathrm{~min}\right.$ at $\left.37^{\circ} \mathrm{C}\right)$. DNA quality was evaluated on $1 \%$ agarose gel and quantity was measured by NanoDrop 1000 (NanoDrop Technologies Inc., USA).

Double-digest restriction-associated DNA sequencing (ddRADseq) protocol described previously by Peterson et al. (2012) was used to detected molecular data. The library was prepared using $200 \mathrm{ng}$ genomic DNA of each sample. DNA was digested at $37^{\circ} \mathrm{C}$ for $3 \mathrm{~h}$ using the $8 \mathrm{U}$ HindIII and $8 \mathrm{U}$ FspBI restriction enzymes. In the next step, digested DNA was ligated to adapters using T4 Ligase for $2 \mathrm{~h}$ at $16^{\circ} \mathrm{C}$. Adapters included Illumina primer sequences and unique barcodes. Purification of ligation products was prepared by AMPure (Beckman Coulter, USA) with beads: sample ratio 1:1. Cleaned DNA was re-suspended in $150 \mu \mathrm{l}$ of water. Fifteen microlite of ligation products were amplified with NeBNext Ultra II Q5 Master Mix (New England Biolabs, UK) using primers with Illumina index sequences due to the single-indexing method. PCR programme: preliminary denaturation $98^{\circ} \mathrm{C} / 30$ s., 16 cycles of denaturation at $98^{\circ} \mathrm{C} / 10 \mathrm{~s}$. and combined annealing and elongation $65^{\circ} \mathrm{C} / 75 \mathrm{~s}$., final elongation $65^{\circ} \mathrm{C} / 5 \mathrm{~min}$., hold at $4^{\circ} \mathrm{C}$. All PCR products were pooled and cleaned-up with AMPure (Beckman Coulter, USA) with bead: sample ratio 1:1 and next 0.6: 1 to size selection of 400-600 bp. A library was quantified on fluorimeter Qubit (ThermoFisher Scientific, USA) by Quant-iT ${ }^{\mathrm{TM}}$ High-Sensitivity dsDNA Assay Kit. A library was diluted to $4 \mathrm{nM}$ and denatured with $0.2 \mathrm{~N} \mathrm{NaOH}$ for $5 \mathrm{~min}$. A denatured library was diluted to 20 pM. $600 \mu \mathrm{l}$ of a prepared library was sequenced using Illumina MiSeq with Miseq Reagent Kit v3 and final PhiX concentration of $12.5 \mathrm{pM}$ and pair reading protocol for 151 cycles.
Quality control of reads was checked in FastQC software (https://www.bioinformatics.babraham.ac.uk/projects/fastqc/; FastQC A Quality Control tool for High Throughput Sequence Data by: S. Andrews). Reads-analysis were prepared with Geneious 11.0 software (https://www.geneious.com, Kearse et al., 2012). The parameters of the substitution model define a rate matrix that can be used to calculate the probability of evolving from one base to another in a given period of time. Most models are variations of two sets of parameters-the equilibrium frequencies and relative substitution rates. Genetic Distance Model: Tamura-Nei. This model also assumes different equilibrium base frequencies. In addition to distinguishing between transitions and transversions, it also allows the two types of transitions ( $\mathrm{A} \leftrightarrow \mathrm{G}$ and $\mathrm{C} \leftrightarrow \mathrm{T}$ ) to have different rates (Tamura and Nei, 1993). Before analyzing, the reads were split by barcode data. Then, the ends were trimmed, paired reads merged and duplicate reads removed (Supplementary Figure 2). The reads were de novo assembled using original data by the Geneious de novo overlap assembler to a high accuracy level (Supplementary Figure 3). A genotype tree was made using the neighbor-joining method with a genetic distance model. The tree was constructed with standard software settings. In this method, neighbors are defined as a pair of leaves with one node connecting them, minimizing the total branch length at each stage of clustering, starting with a star-like tree. The branch lengths and an unrooted tree topology can quickly be obtained by using this method without assuming a molecular clock (Saitou and Nei, 1987).

\section{Meteorological Data}

Field trials were conducted in Radzików, Central Poland. The generative stages of hybrids belonging to the middle-early group were as follows: silking (R1)-I decade of July, blister (R2)-II decade of July, milk (R3)-III decade of July, dough (R4)-I decade of August, dent (R5)-from the II decade of August until the end of I decade of September. Physiological maturity (R6) stage and harvesting time were in the II decade of September. The generative stages of hybrids belonging to the middle-late group started 7 days later (II decade of July) and lasted until the half of the III decade of September. The average temperatures and rainfalls during this time are presented in Figure 2.

\section{Statistical Analyses}

Comparison between inbred lines was done using Fisher's least significant difference test using InfoStat software. In addition to the mold-covered surface proportion of the maize grain, fumonisin content in the infected maize grain meal and the content of the infected maize grain meal, the so-called ToxinMold-Index (TMI), was also calculated according to the method described by Arpad et al. (1997), by multiplying the sum of mycotoxin contents, expressed in $\mathrm{mg}$ per $\mathrm{kg}$, by the proportion of mold-covered surfaces of maize ear expressed as percentage of the total surface where: $\mathrm{TMI}=\left(\mathrm{FB}_{1}+\mathrm{FB}_{2}+\mathrm{FB}_{3}\right)^{*} \mathrm{~A} ; \mathrm{FB}_{1}, \mathrm{FB}_{2}$, $\mathrm{FB}_{3}$ content in maize meal obtained from grain and corn cobs; A - proportion of the mold-covered area of ears in \% of the total areas of ears. 


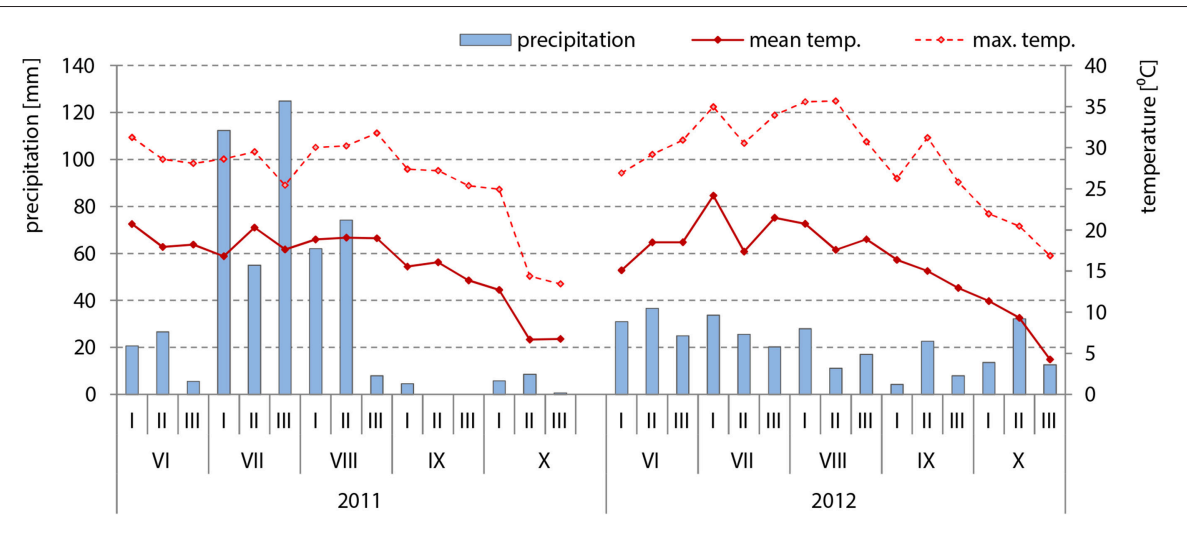

FIGURE 2 | Weather conditions in the years 2011 and 2012 when the FER resistance assessment of 98 maize inbred lines was carried out under field conditions with a natural infection and after inoculation with F. verticillioides: mean temperature and precipitation data from sowing time (April) till harvesting time (October) were shown.

Differences between inbred lines within years were determined with Fisher's protected least significant difference (LSD) test. Linear correlation coefficients were determined for the relationship between FER severity and fumonisin concentration in grain and cobs sampled from non-inoculated and inoculated plants in 2012 using InfoStat software.

\section{RESULTS}

\section{Fusarium Ear Rot Severity and Fumonisin Contamination}

All inoculations resulted in visible disease symptoms (DI $=100 \%)$. A summary of statistical data such as mean, SD, minimum and maximum of ear rot ratings of flint $(n=23)$, dent $(n=39)$, IDT $(n=9)$, Lancaster $(n$ $=4)$, SSS $(n=8)$, SSS/IDT $(n=5)$, and unknown $(n=10)$ heterotic groups under natural infection (non-inoculated) and inoculated with F. verticillioides in 2011 and 2012 are shown in Table 1. The Variability of ear rot incidence was observed between, and within, heterotic groups. Figure 1 shows ears representing individual origin groups and symptoms of the disease after inoculation.

In July, when the primary infection usually takes place, maximum temperatures were higher in 2012 than in 2011 by ca. $5^{\circ} \mathrm{C}$ and favored the development of $F$. verticillioides, used for artificial infection (Figure 2). In 2011, high precipitation in July $(112 \mathrm{~mm}, 55 \mathrm{~mm}$ and $127 \mathrm{~mm}$ in the first, second and third decades, respectively) and August $(62 \mathrm{~mm}$ and $74 \mathrm{~mm}$ in the first and second decades, respectively) did not stimulate disease development. The effects of maize heterotic groups and inbred lines on disease severity differed between years.

Significant differences in FER severity were observed among inbred lines and heterotic groups evaluated under natural infection and after inoculation in both years. Fusarium ear rot severity was significantly higher in 2012 than in 2011 with means of 4.9 and $1.8 \%$ of the ear exhibiting disease symptoms under natural conditions, respectively, and 15.2 and $8.07 \%$ after inoculation with $F$. verticillioides. Under natural infection, FER severity for all 98 inbred lines ranged from 1.6 to $45.5 \%$ of the ear exhibiting disease symptoms in 2012 and from 0.0 to $7.0 \%$ of the ear in 2011. After inoculation, FER severity ranged from 3.0 to $63.0 \%$ of the ear exhibiting disease symptoms in 2012 and from 1.4 to $50.5 \%$ of the ear in 2011. In 2012 the means of ear rot severity of evaluated groups ranged from 10.9 to $30.99 \%$ of ears covered by disease symptoms. The most susceptible group was SSS/IDT (Table 1). The most resistant inbred lines belonged, mostly, to the unknown heterotic group. The SD in all heterotic groups ranged from 1.13 to 2.2 and from 2.10 to 6.76 under natural infection in 2011 and 2012, respectively. They were much higher after artificial inoculation; ranging from 2.32 to 17.89 in 2011 and 2012, respectively.

On average, for more than $91 \%$ of all evaluated inbred lines, the symptoms of the disease did not exceed $10 \%$ of the total ear area under natural infection (Figure 3). In 2011, for $73 \%$ of all evaluated inbred lines, the symptoms of the disease covered $<10 \%$ of the ear area, and in 2012 the same applied to $43.9 \%$ of lines tested. In 2012, for $10.2 \%$ of evaluated inbred lines, the disease symptoms were observed within a range of $26-50 \%$ of ear area.

A simple correlation analysis and a principal component analysis (PCA, Figure 4) were performed to decipher the relationships between FER severity under natural infection and after inoculation. Using Pearson's correlation coefficients it was shown that the FER severity under natural infection in 2012 was significantly correlated with FER after the $F$. verticillioides kernel inoculation $\left(r=0.48^{*}, p<0.005\right)$. Furthermore, the results of FER scored in 2011 after inoculation was positively correlated with the results obtained in 2012 $\left(0.46^{*}, p<0.005\right)$. The purpose of the PCA was to group individual parameters in a more comprehensive manner. Two principal components (PC) explained $69.2 \%$ of the variability. The length of the vectors represents the PCA loadings of the variables on the first two principal components, PC1 (44.5\%) had strong positive loading from FER after inoculation in 2011 and 2012 and FER under natural infection in 2012. PC2 (24.7\%) had positive loading from FER under natural infection in 2011. The highest diversity among inbreds was 
TABLE 1 | Summary statistics of ear rot ratings of $n=98$ inbred lines that belong to flint, dent, Lancaster, SSS, IDT, SSS/IDT and "unknown" heterotic groups under natural infection and inoculated with F. verticillioides in 2011 and 2012 years.

\begin{tabular}{|c|c|c|c|c|c|c|c|c|c|c|}
\hline \multirow[t]{4}{*}{ No. } & \multirow[t]{4}{*}{ Heterotic group } & \multirow[t]{4}{*}{$\mathbf{n}$} & \multicolumn{8}{|c|}{ Fusarium ear rot (\%) } \\
\hline & & & \multicolumn{4}{|c|}{ non-inoculated } & \multicolumn{4}{|c|}{ inoculated } \\
\hline & & & \multicolumn{2}{|c|}{2011} & \multicolumn{2}{|c|}{2012} & \multicolumn{2}{|c|}{2011} & \multicolumn{2}{|c|}{2012} \\
\hline & & & mean $^{a}$ & range & mean $^{a}$ & range & mean $^{\mathrm{a}}$ & range & mean $^{a}$ & range \\
\hline 1 & dent & 39 & $2.2 \pm 0.62$ & $0.0-7.0$ & $5.4 \pm 6.76$ & $1.2-48.0$ & $6.8 \pm 4.35$ & $1.2-22.0$ & $14.9 \pm 11.75$ & $2.0-63.0$ \\
\hline 2 & flint & 23 & $1.4 \pm 0.56$ & $0.0-4.5$ & $4.3 \pm 3.47$ & $1.6-45.5$ & $9.1 \pm 6.85$ & $2.0-45.5$ & $16.4 \pm 9.35$ & $3.0-58.0$ \\
\hline 3 & IDT & 9 & $1.8 \pm 0.80$ & $0.0-4.5$ & $3.4 \pm 2.23$ & $1.6-18.0$ & $6.3 \pm 4.27$ & $1.2-18.0$ & $11.3 \pm 8.06$ & $4.0-34.0$ \\
\hline 4 & lancaster & 4 & $1.9 \pm 0.75$ & $0.0-7.0$ & $8.6 \pm 7.53$ & $1.2-22.0$ & $16.3 \pm 17.89$ & $2.0-50.5$ & $10.9 \pm 7.54$ & $5.0-22.0$ \\
\hline 5 & SSS & 8 & $1.8 \pm 0.78$ & $0.0-7.0$ & $4.5 \pm 5.54$ & $1.6-26.0$ & $6.8 \pm 5.20$ & $1.4-15.8$ & $14.7 \pm 12.89$ & $3.0-43.0$ \\
\hline 6 & SSS / IDT & 5 & $1.3 \pm 0.60$ & $0.0-2.0$ & $7.5 \pm 6.50$ & $1.6-22.0$ & $21.7 \pm 8.47$ & $7.0-45.5$ & $31.0 \pm 16.55$ & $11.4-63.0$ \\
\hline 7 & unknown & 10 & $1.8 \pm 0.97$ & $0.0-7.0$ & $3.5 \pm 2.10$ & $1.6-18.0$ & $4.2 \pm 2.32$ & $1.3-9.2$ & $11.2 \pm 5.01$ & $3.0-26.0$ \\
\hline \multicolumn{2}{|l|}{ Mean } & 98 & $4.93 \pm 6.13$ & $1.6-45.5$ & $1.82 \pm 1.13$ & $0.0-7.0$ & $8.07 \pm 7.77$ & $1.4-50.5$ & $15.15 \pm 11.55$ & $3.0-63.0$ \\
\hline \multicolumn{2}{|c|}{ LSD Fisher $p<0.05$} & 98 & 5.941 & & 1.709 & & 7.845 & & 6.319 & \\
\hline
\end{tabular}

a Mean ear rot severity is reported as the average of the entry least square means (back-transformed to the original 0-100\% disease severity scale).

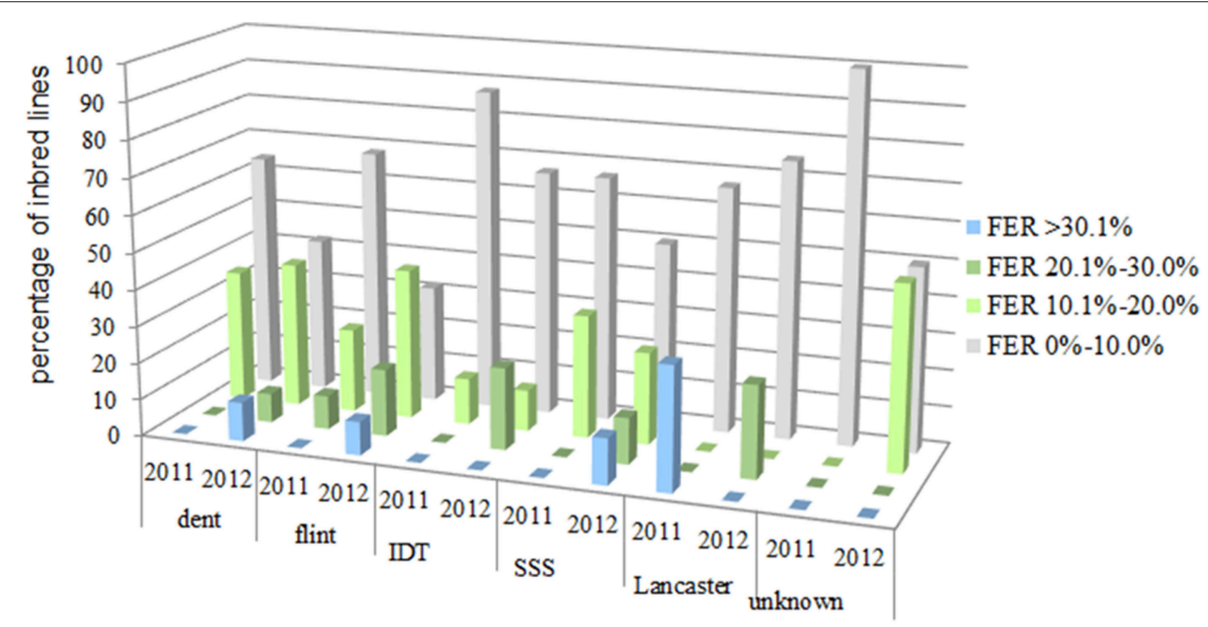

FIGURE 3 | Distribution for percentage data of inbred lines for which the disease symptoms covering: 0.0-10.0\%, 10.1-20.0\%, 20.1-30.0\% and above 30.1\% of the total ear area after kernel inoculation with F. verticillioides in 2011 and 2012 belonging to different heterotic groups: 23 flint, 39 dent, 4 Lancaster, 9 lodent (IDT), 8 Stiff Stalk Synthetic (SSS) 5 SSS/IDT and 10 unknown heterogenic group.

associated with FER, evaluated after inoculation in 2012. The most susceptible and moderately resistant inbred lines from each group of origin were selected for fumonisin content analysis.

Ear rot severity of these genotypes in 2011 and 2012, fumonisin contamination in grain and cobs sampled from inoculated and non-inoculated plants in 2012 and TMI index are shown in Table 2. Under natural infection, cobs were more contaminated with fumonisin $\mathrm{B}_{1}$ than grain samples. The frequency of cob samples contaminated with $\mathrm{FB}_{1}$ was $66.7 \%$ and for grain samples contaminated with $\mathrm{FB}_{1}$ it was $29.6 \%$. Maize inbred lines accumulated different levels of fumonisins in grain and in cobs. In grains sampled from inbred lines of dent, flint, SSS, IDT, SSS/IDT and Lancaster heterotic groups after kernel inoculation with $F$. verticillioides, the $\mathrm{FB}_{1}$ contamination ranged from 0.99 to $99.04 \mathrm{mg} / \mathrm{kg}, \mathrm{FB}_{2}$ contamination ranged from 0.05 to $21.44 \mathrm{mg} / \mathrm{kg}$ and $\mathrm{FB}_{3}$ from 0.0 to $2.21 \mathrm{mg} / \mathrm{kg}$. In cob samples $\mathrm{FB}_{1}$ contamination ranged from 0.02 to 23.05 $\mathrm{mg} / \mathrm{kg}, \mathrm{FB}_{2}$ from 0.0 to $4.5 \mathrm{mg} / \mathrm{kg}$ and $\mathrm{FB}_{3}$ from 0.0 to 1.82 $\mathrm{mg} / \mathrm{kg}$. Based on the TMI index it was possible to identify highly resistant and susceptible genotypes. A hierarchical clustering of the inbred lines representing resistant and very susceptible genotypes belonging to each heterotic group was created based on the TMI index (Figure 5). Inbreds with low fumonisin content belonged to two separate clusters with low distance between them. Susceptible inbreds belonged to the very inconsistent group with large distances from each other.

In 2012, ear rot severity positively correlated with fumonisin content in grain samples $\left(\mathrm{FB}_{1}, \mathrm{FB}_{2}\right.$, and $\left.\mathrm{FB}_{3}\right)$, with $\mathrm{r}$ factor ranging from $r=0.82^{* * *}$ to $0.91^{* * *}$. The correlations between 


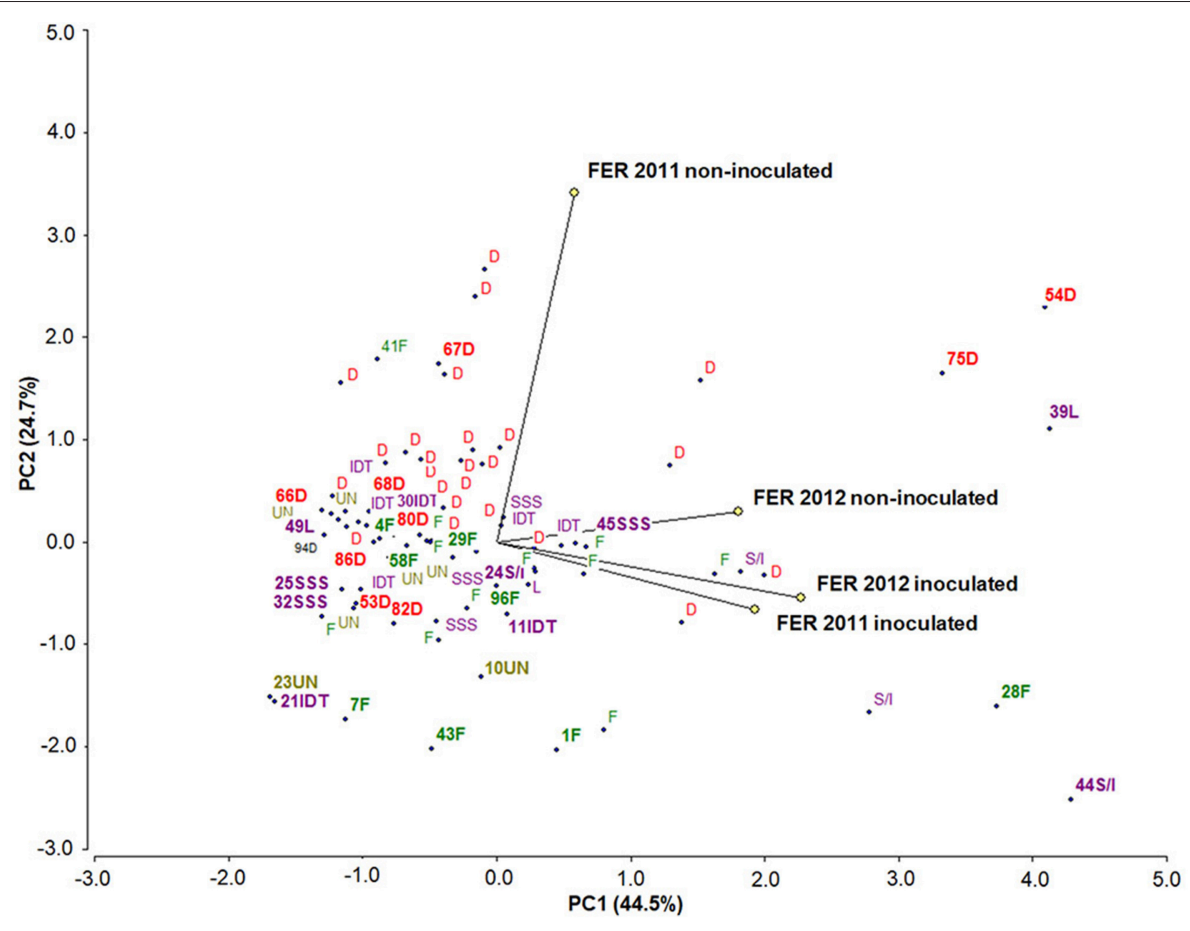

FIGURE 4 | Scatter plot of the first principal component scores derived from rating the FER severity, showing the dispersion of 98 inbred lines belonging to different heterotic groups: 23 flint (F), 39 dent (D), 4 Lancaster (L), 9 lodent (IDT), 8 Stiff Stalk Synthetic (SSS), 5 SSS/IDT and 10 unknown (UN). Colored dots represent individual subjects with a subject identification group. Colored dots represent individual subjects with a subject identification number were selected for fumonisin content analysis as a moderate resistant (negatively correlated with FER) and susceptible one (positively correlated with FER). The length of the vectors represents the PCA loadings of the variables on the first two principal components, which explain $69.2 \%$ of the variability.

individual fumonisins were also highly significant (in grain samples they ranged from $r=0.90^{* * *}$ to $r=0.93^{* * *} p<0.005$ and for cobs they ranged from $r=0.92^{* * *}$ to $\left.0.97^{* * *} p<0.005\right)$. No correlations were found between the ear rot severity and toxin content in maize cobs.

\section{Molecular Markers and Population Genotyping}

The level of genetic heterogeneity among inbreds with contrasting ear rot resistance was studied using the ddRADseq genome sampling method. They belonged to the following groups: flint, dent, Lancaster, IDT, SSS and SSS/IDT. The range of quality values across all bases at each position for our results in the FastQ file was high and it was conceivable to observe a difference for a number of reads for genotypes, even if they belonged to the same origin group (Figure 6; Supplementary Figures 2, 3). The genotype tree was made using the neighbor-joining method with a genetic distance model. Branch length expressed nucleotide differences. The relative genetic distances between haplotypes were high. One haplotype contained moderately resistant inbred lines belonging to the IDT historical heterotic group (lines 11, 21, 30), SSS / IDT (line 22) and SSS (line 32). Susceptible inbreds belonged to the SSS (line 45) and SSS/IDT groups (line 44) and were classified separately. Likewise, lines from the Lancaster group, described as resistant (line 49) and susceptible (line 39) did not belong to the same haplotype. Furthermore, in the dent group, resistant and susceptible lines were separate. Interestingly, resistant lines from the flint heterotic group belonged to the same haplotype and susceptible flint line was classified separately. Haplotypes of the genotype tree corresponded to the data of the co-ancestry heat map (Figure 7).

\section{DISCUSSION}

The rapid increase of maize cultivation area, the use of inappropriate crop rotation and global warming have resulted in a rise in frequency of diseases including ear rot fusariosis (Fusarium spp.). Using highly resistant hybrids is one of the most important methods of integrated plant protection (Vasileiadis et al., 2011; Zijlstra et al., 2011).

Artificial inoculations are necessary for the evaluation of maize FER under field conditions because the disease symptoms under natural infection are not repeatable and largely depend on local environmental factors (Santiago et al., 2015). Different methods of inoculation were developed and described (Drepper and Renfro, 1990; Schaafsma et al., 1993; Munkvold and Carlton, 1997; Munkvold et al., 1997; Reid et al., 2002). These methods correspond with natural disease development processes. Flowering and kernel drying are critical periods for disease development and kernel contamination with fumonisins (Munkvold, 2003b; Bush et al., 2004; De La Campa et al., 2005; 


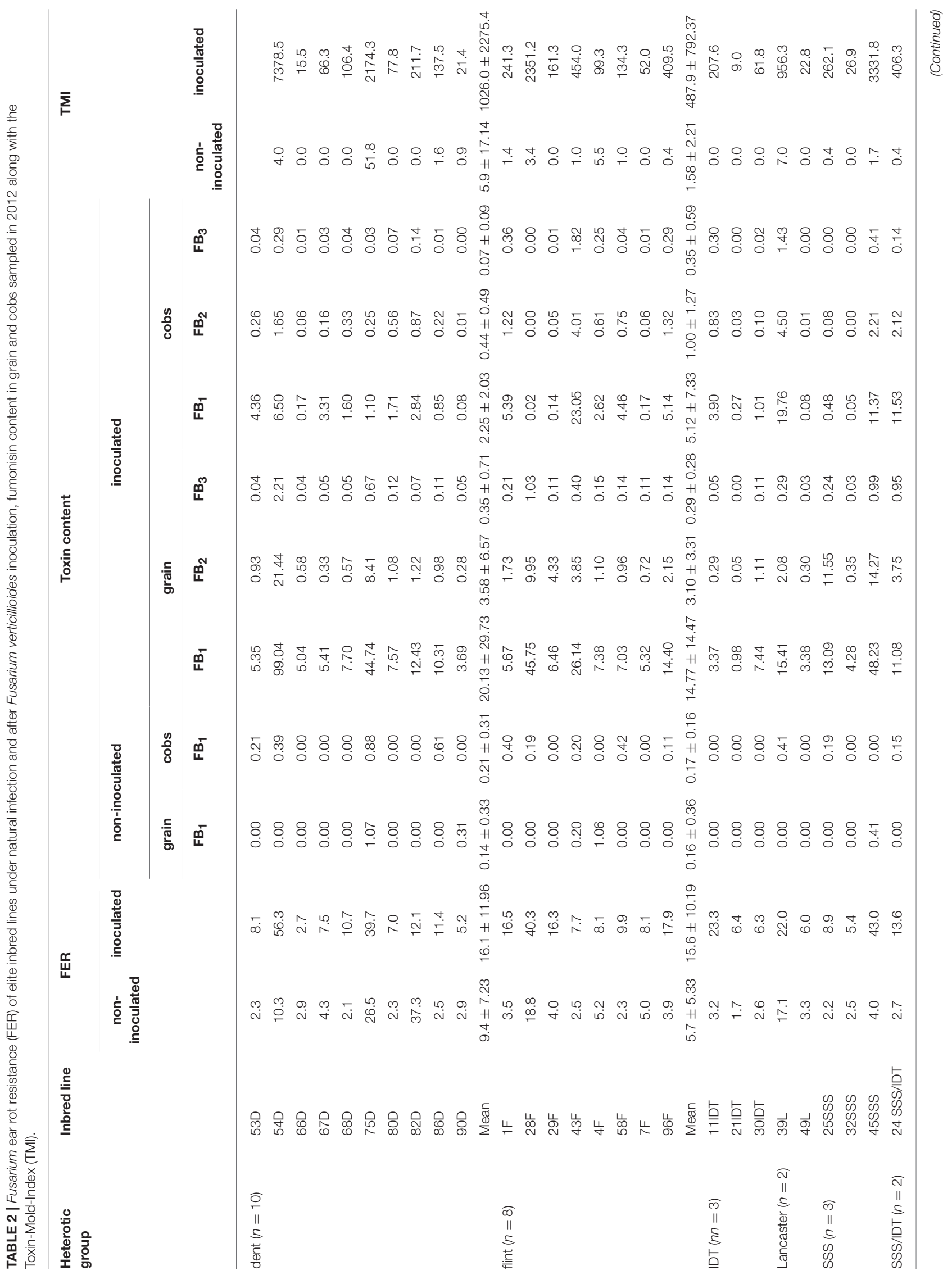




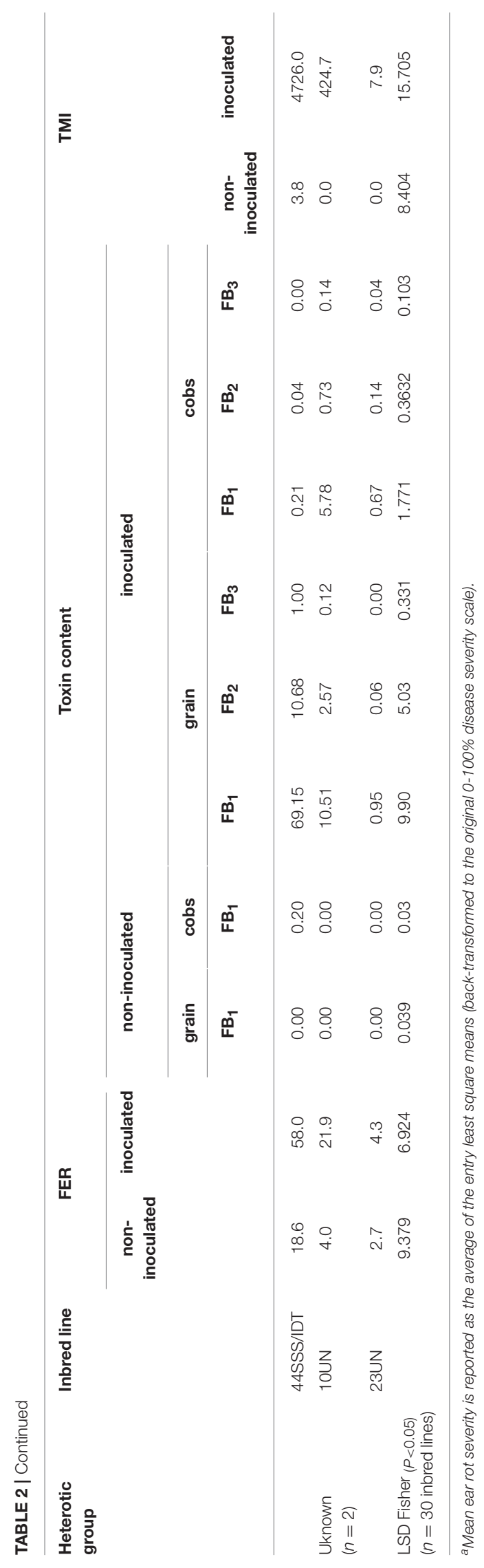

Maiorano et al., 2009a,b; Venturini et al., 2011; Cao et al., 2014a,b; Czembor and Matusiak, 2014). Weather conditions affect all of these processes. We could not confirm that high rainfall or high temperature just before harvest are conducive for fumonisin contamination, particularly concerning rainfall data for 2011 and 2012 .

In our study, the inoculation technique was very effective, both for FER assessment and for the assessment of the fumonisin contamination of the grain. Kernel samples collected from the most resistant inbred line were also not heavily contaminated with $\mathrm{FBs}$ after inoculation. The correlation between $\mathrm{FB}_{1}, \mathrm{FB}_{2}$ and $\mathrm{FB}_{3}$ contamination of grain samples and FER severity were highly significant. No significant correlations were observed between the content of fumonisins in samples collected from cobs, both under natural infection and after inoculation. Also in other studies the correlation between the concentration of fumonisin and the severity of FER after inoculation is usually found. Desjardins et al. (2002) and Desjardins and Plattner (2000) reported a very high correlation between fumonisin concentration and visible symptoms, with fumonisin levels being higher in symptomatic kernels and lower in symptomless kernels, respectively. However, in some studies the correlations were not present (Clements et al., 2003a,b).

NGS techniques provide new tools for overcoming the long selection process and increase the breeding efficiency. The knowledge of the QTL genomic location is essential to investigate their potential, as well as their effectiveness toward FER and environmental conditions examined locally (Campos-Bermudez et al., 2013). Here, ddRADseq genome sampling method was deployed to distinguish genetic differences between genotypes with contrasting ear rot resistances (selected based on the field evaluation after inoculation and fumonisin quantification) but also belonging to different heterotic groups: flint and dent groups, as well as to the historical heterotic groups, such as Lancaster, IDT, SSS. The genetic distances between haplotypes were large, indicating an ancient gene pool and possible interspecific hybridization events in maize ancestry. However, among the among the lines of the flint group, as well as in the historical groups, it was possible to find relationship between moderately resistant and susceptible genotypes. Lanubile et al. (2012) summarized reports on mapping disease resistance genes in maize. Using SNPs it was found that QTL located on chromosomes 1, 5, and 9 play significant roles in FER resistance (Zila et al., 2013, 2014). Seven SNPs in six genes associated with FER resistance were identified on chromosomes 4, 5, and 9 based on evaluation of the collection of 1,687 maize inbred lines. Maschietto et al. (2017) found eight QTL associated with FER resistance and $\mathrm{FB}_{1}$ contamination and Lanubile et al. (2014) mapped 24 candidate genes for FER resistance on the same chromosomal regions. Based on these findings, it is possible to conclude that the QTL with the highest effect for FER resistance was located distally on Chromosome 1. Wisser et al. (2006) postulated that known disease resistance QTL covered $89 \%$ of the maize genome. This high degree of coverage is unlikely and possibly related to the relatively 


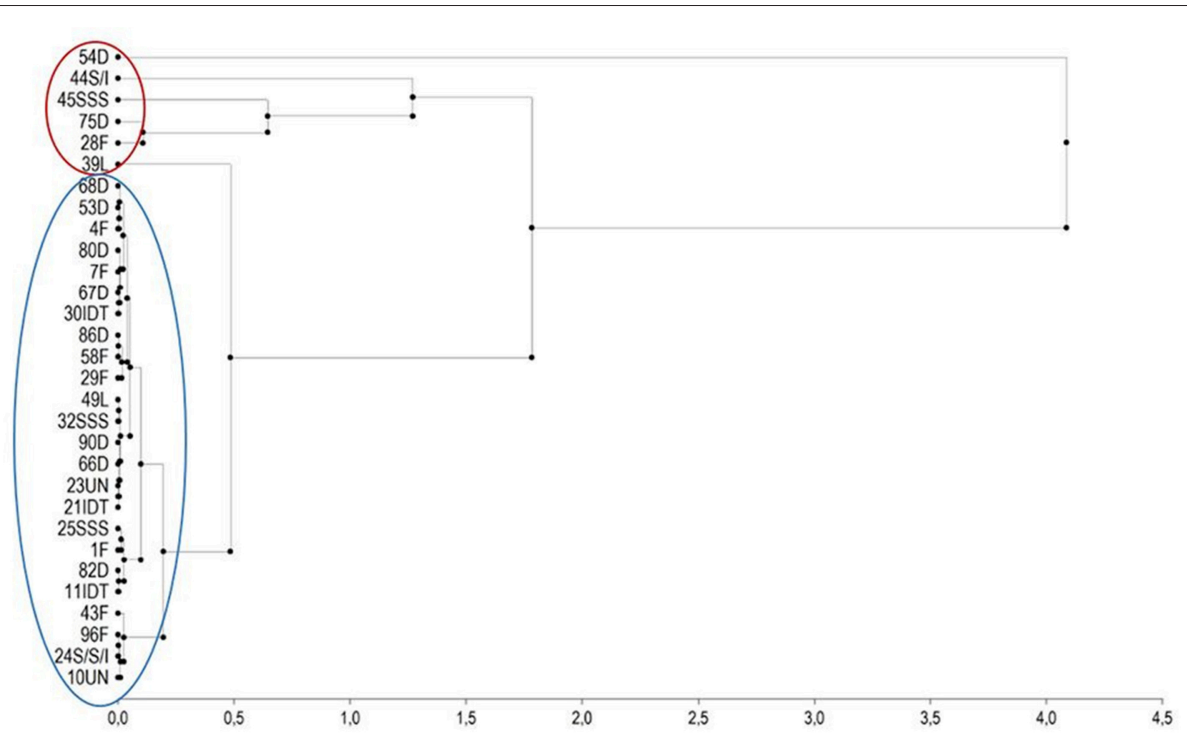

FIGURE 5 | Hierarchical clustering of the inbred lines representing moderately resistant and very susceptible genotypes selected from the collection of 98 inbred based on the disease assessment of non-inoculated and inoculated ears with F. verticillioides in 2011 and 2012 years using the Euclidean distance of the elements of relationship matrix A (based on TMI index genotypes in a red cluster represent a very susceptible group). Thirty inbred lines belonging to different heterotic groups 10 dent (D), 8 flint (F), 3 lodent (IDT), 2 Lancaster (L), 3 Stiff Stalk Synthetic (SSS), 2 SSS/IDT, and 2 unknown (UN). Red color circle: susceptible group, blue color circle: moderate resistant group.

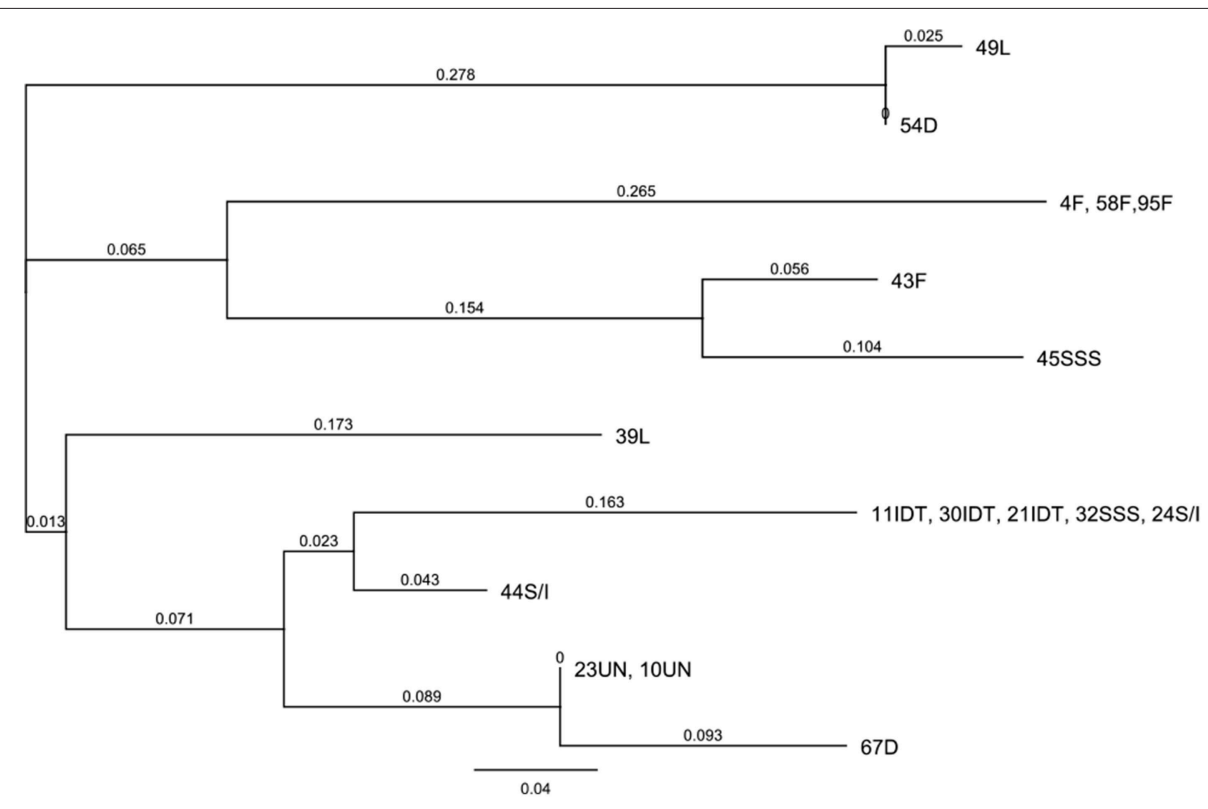

FIGURE 6 | Hierarchical clustering of the inbred lines representing moderate resistant (MR) and susceptible (S) genotypes using Neighbor-joining tree representing phylogenetic distances between objects of relationship matrix.

low precision and accuracy of QTL mapping and not taking into account other relevant factors. Our study stands in line with this hypothesis. It is because of the strong influence of environmental factors, plant phenotype and/or interaction of factors, on the spread of the disease in different locations, where FER resistance studies are conducted. That's why QTL mapping results have often been contradictory and their verification in different genetic backgrounds is necessary
(Pérez-Brito et al., 2001; Robertson-Hoyt et al., 2006; Ding et al., 2008; Santiago et al., 2013). A new approach to identify candidate genes and QTL for resistance is represented by plant metabolome investigation after pathogen infection (Lanubile et al., 2017) and differential transcriptomic analyses showing genes potentially involved in resistance processes.

Maize breeding has undergone significant changes through the last four decades and so have the materials used. Facing 


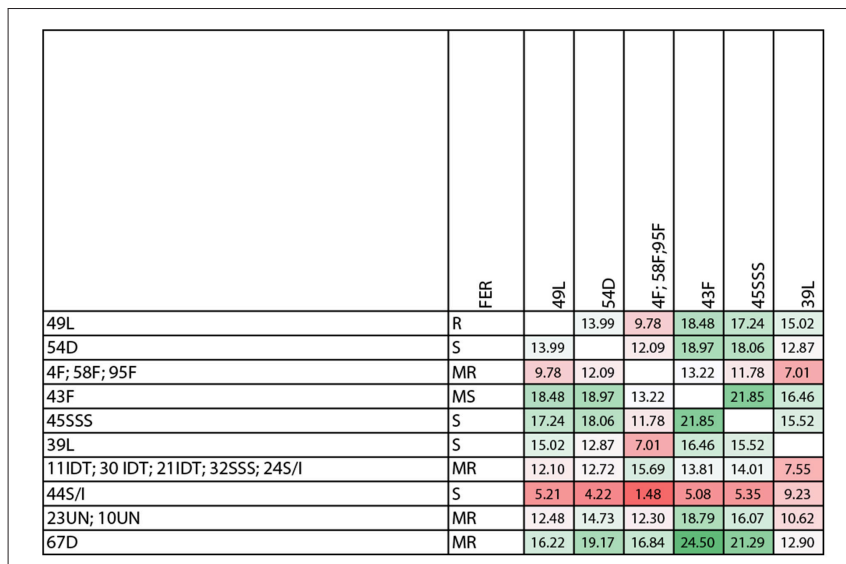

FIGURE 7 | Co-ancestry heat map (the color code corresponds to the degrees of similarity-from green means the most similar to red as the least similar). Inbred lines belong to heterotic group: dent (D), flint (F), lodent (IDT), Lancaster, Stiff Stalk Synthetic (SSS), SSS/IDT and unknown pedigree (un).

the dramatic climate changes it becomes obvious that pathogen populations are being changed as well, along with the maize lines grown. Fusarium ear rot resistance remains one of the most important traits in constant selection of materials and sources of this resistance have never been compared until now. This research has demonstrated that currently grown Polish inbreds and also the ones grown in the past may serve as a valid source of resistance to FER. A strong association was observed between visible Fusarium symptoms after inoculation with fumonisin concentration in grain samples, suggesting that selection in maize for reduced visible molds should reduce the risk of mycotoxin contamination. Under natural infection, the cobs contained more fumonisin $B_{1}$ than grain samples. This finding suggests that $F$. verticillioides contaminates grain more intensively when applied artificially. When found naturally, it tends to overgrow preferably the cobs and not the grain. Moreover, under natural infection one has to take into account the presence of other species like F. graminearum, F. poae, F. temperatum or F. proliferatum, which may compete for nutrients and it has been shown that mycotoxin biosynthesis is one of the strategies used by the pathogen to get the advantage over a competitor. To validate this hypothesis a different experimental approach will be established in the future research. Resistance to FER and to fumonisin accumulation is determined by many factors, such as: environmental conditions, infection timing, presence of other competitive species, ear morphology, the kernel's structure and nutrient components, as well as by the interaction between all these factors, which makes drawing conclusions from a single experimental approach challenging. The use of NGS technique in combination with disease symptom screening and mycotoxin

\section{REFERENCES}

Ali, F., and Yan, J. (2012). Disease resistance in maize and the role of molecular breeding in defending against global threat. $J$. Integr. Plant Biol. 54, 134-151. doi: 10.1111/j.1744-7909.2012.0 contamination allows for fast analysis which genotypes will be most valuable in incorporating the resistance into current breeding programs.

\section{DATA AVAILABILITY}

This manuscript contains previously unpublished data. The name of the repository and accession number are not available.

\section{AUTHOR CONTRIBUTIONS}

EC designed and conducted field experiments. AW conducted toxins analyses. MP, UP, and JC performed the molecular studies. EC, AW, MP, and UP interpreted the data. EC, AW, MP, UP, JC, and LS drafted the manuscript, designed figures and tables. All authors read and approved the final manuscript.

\section{FUNDING}

This work was funded by Polish Ministry of Agriculture and Rural Development.

\section{ACKNOWLEDGMENTS}

This work was funded by The Polish Ministry of Agriculture and Rural Development.

\section{SUPPLEMENTARY MATERIAL}

The Supplementary Material for this article can be found online at: https://www.frontiersin.org/articles/10.3389/fmicb. 2019.00449/full\#supplementary-material

Supplementary Figure 1 | Seven-point scale used to score FER: $1=$ no visible disease symptoms, $2=1-3 \%, 3=4-10 \%, 4=11-25 \%, 5=26-50 \%$, $6=51-75 \%$, and $7=76-100 \%$ of kernels exhibiting visual symptoms of infection, such as brown, pink, or reddish discolouration of kernels and pinkish or white mycelial growth (Clements et al., 2003a,b).

Supplementary Figure 2 | Number of reads before (blue) and after (red) removing duplicates from data to reduce the impact of a heterogenous PCR step prior to sequencing.

Supplementary Figure 3 | The range of quality values across all bases at each position in the FastQ file. The $y$-axis shows the quality scores. The higher the score, the better the base call. The background of the graph divides the $y$ axis into very good quality calls (green), calls of reasonable quality (orange), and calls of poor quality (red). The elements of the plot are as follows: the yellow box represents the inter-quartile range (25-75\%), the upper and lower whiskers represent the 10 and $90 \%$ points. The blue line represents the mean quality.

Supplementary Table 1 | 1. Table of relevant maize accession numbers with indexes and barcodes used, which allow to de-multiplexing NGS resultant sequences. 2. Link to the cloud with raw resultant sequencing data, which is available for everyone after logging to BaseSpace Cloud.

Ariño, A., Herrera, M., Juan, T., Estopañan, G., Carramiñana, J. J., and Rota, C. (2009). Influence of agricultural practices on the contamination of maize by fumonisin mycotoxins. J. Food Prot. 72, 898-902. doi: 10.4315/0362-028X-72.4.898

Arpad, B., Rafai, P., Kovacs, G., and Halasz, A. (1997). A new method for evaluation of the resistance of maize hybrids for fusarial ear rot 
- the Toxin -Mould-Index (TMI). Period. Politech. Ser. Chem. Eng. 41,3-10.

Balconi, C., Berardo, N., Locatelli, S., Lanzanova, C., Torri, A., and Redaelli, R. (2014). Evaluation of ear rot (Fusarium verticillioides) resistance and fumonisin accumulation in Italian maize inbred lines. Phytopathol. Mediterr. 53, 14-26. doi: 10.14601/Phytopathol_Mediterr/11776

Bennett, J. W., and Klich, M. (2003). Mycotoxins. Clin. Microbiol. Rev. 16, 497-516. doi: 10.1128/CMR.16.3.497-516.2003

Bolduan, C., Miedaner, T., Schipprack, W., Dhillon, B. S., and Melchinger, A. E. (2009). Genetic variation for resistance to ear rots and mycotoxins contamination in early European maize inbred lines. Crop Sci. Soc. Am. 49, 2019-2028. doi: 10.2135/cropsci2008.12.0701

Bush, B. J., Carson, M. L., Cubeta, M. A., Hagler, W. M., and Payne, G. A. (2004). Infection and fumonisin production by Fusarium verticillioides in developing maize kernels. Phytopathology 94, 88-93. doi: 10.1094/PHYTO.2004. 94.1.88

Butrón, A., Reid, L. M., Santiago, R., Cao, A., and Malvar, R. A. (2015). Inheritance of maize resistance to Gibberella and Fusarium ear rots and kernel contamination with deoxynivalenol and fumonisins. Plant Pathol. 64, 1053-1060. doi: 10.1111/ppa.12351

Butrón, A., Santiago, R., Mansilla, P., Pintos-Varela, C., Ordás, A., and Malvar, R. A. (2006). Maize (Zea mays L.) genetic factors for preventing fumonisin contamination. J. Agric. Food Chem. 54, 6113-6117. doi: 10.1021/jf06 11163

Campos-Bermudez, V. A., Fauguel, C. M., Tronconi, M. A., Casati, P., Presello, D. A., and Andreo, C. S. (2013). Transcriptional and metabolic changes associated to the infection by Fusarium verticillioides in maize inbreds with contrasting ear rot resistance. PLoS ONE 8:e61580. doi: 10.1371/journal.pone.0061580

Cao, A., Butrón, A., Ramos, A. J., Marín, S., Souto, C., and Santiago, R. (2014a). Assessing white maize resistance to fumonisin contamination. Eur. J. Plant Pathol. 138, 283-292. doi: 10.1007/s10658-013-0328-y

Cao, A., Santiago, R., Ramos, A. J., Souto, X. C., Aguín, O., Malvar, R. A., et al. (2014b). Critical environmental and genotypic factors for Fusarium verticillioides infection, fungal growth and fumonisin contamination in maize grown in northwestern Spain. Int. J. Food Microbiol. 177, 63-71. doi: 10.1016/j.ijfoodmicro.2014.02.004

Chen, J., Ding, J., Li, H., Li, Z., Sun, X., Li, J., et al. (2012). Detection and verification of quantitative trait loci for resistance to Fusarium ear rot in maize. Mol. Breed. 30, 1649-1656. doi: 10.1007/s11032-012-9748-1

Clements, M. J., Campbell, K. W., Maragos, C. M., Pilcher, C., Headrick, J. M., Pataky, J. K., et al. (2003a). Influence of crylab protein and hybrid genotype on fumonisin contamination and Fusarium ear rot of corn. Crop Sci. 43, 1283-1293. doi: 10.2135/cropsci2003.1283

Clements, M. J., Kleinschmidt, C. E., Pataky, J. K., and White, D. G. (2003b). Evaluation of inoculation techniques for Fusarium ear Rot and fumonisin contamination of corn. Plant Dis. 147-153. doi: 10.1094/PDIS.2003.87.2.147

Czembor, E., and Frasinski, S. (2018). Polish maize elite inbred lines as a source of resistance for ear rot (Fusarium spp.) and common smut (Ustilago maydis). J. Plant Prot. 58, 22-27. doi: 10.14199/ppp-2018-002

Czembor, E., and Matusiak, M. (2014). Kinetics of red ear rot of maize caused by Fusarium graminearum and deoxynivalenol accumulation in the grain [Dynamika rozwoju fuzariozy kolb kukurydzy powodowanej przez Fusarium graminearum oraz akumulacji deoksyniwalenolu w ziarnie. Biul. IHAR. 274, 27-39.

Czembor, E., Matusiak, M., and Ochodzki, P. (2013b). Resistance of maize hybrids to ear rot caused by Fusarium graminearum and F. verticillioides in Poland in years 2008-2009 [Odporność mieszanców kukurydzy na fuzarioze kolb powodowana przez Fusarium graminearum i F. verticillioides w Polsce w latach 2008-2009]. Biul. IHAR. 270, 55-74.

Czembor, E., Matusiak, M., and Warzecha, R. (2013a). Looking for sources of resistance to ear rot and stalk rot on the basis of the pedigree selection [Poszukiwanie zródeł odporności kukurydzy na fuzarioze kolb i zgorzel podstawy łodyg metoda rodowodowa]. Biul. IHAR. 269, 123-140.

Czembor, E., Stepie,n, Ł., and Waśkiewicz, A. (2014). Fusarium temperatum as a new species causing ear rot in Poland. Plant Dis. 98:1001. doi: 10.1094/PDIS-11-13-1184-PDN

Czembor, E., Stepien, Ł., and Waśkiewicz, A. (2015). Effect of environmental factors on Fusarium species and associated mycotoxins in maize grain grown in Poland. PLoS ONE 10:e0133644. doi: 10.1371/journal.pone.01 33644

de Galarreta, J. I. R., Butrón, A., Ortiz-Barredo, A., Malvar, R. A., Ordás, A., Landa, A., et al. (2015). Mycotoxins in maize grains grown in organic and conventional agriculture. Food Control 52, 98-102. doi: 10.1016/j.foodcont.2014.12.016

De La Campa, R., Hooker, D. C., Miller, J. D., Schaafsma, A. W., and Hammond, B. G. (2005). Modeling effects of environment, insect damage, and Bt genotypes on fumonisin accumulation in maize in Argentina and the Philippines. Mycopathologia 159, 539-552. doi: 10.1007/s11046-005-2150-3

Desjardins, A. E., Munkvold, G. P., Plattner, R. D., and Proctor, R. H. (2002). FUM1 - a gene required for fumonisin biosynthesis but not for maize ear rot and ear infection by Gibberella moniliformis in field tests. Mol. Plant Microbe Interact. 15, 1157-1164. doi: 10.1094/MPMI.2002.15.11.1157

Desjardins, A. E., and Plattner, R. D. (2000). Fumonisin $B_{1}$-sonproducing strains of Fusarium verticillioides cause maize (Zea mays) ear infection and ear rot. J. Agric. Food Chem. 48, 5773-5780. doi: 10.1021/jf000619k

Ding, J. Q., Wang, X. M., Chander, S., Yan, J. B., and Li, J. S. (2008). QTL mapping of resistance to Fusarium ear rot using a RIL population in maize. Mol. Breed. 22, 395-403. doi: 10.1007/s11032-008-9184-4

Dorn, B., Forrer, H. R., Schurch, S., and Vogelgsang, S. (2009). Fusarium species complex on maize in Switzerland: occurrence, prevalence, impact and mycotoxins in commercial hybrids under natural infection. Eur. J. Plant Pathol. 125, 51-61. doi: 10.1007/s10658-009-9457-8

Drepper, W. J., and Renfro, B. L. (1990). Comparison of methods for inoculation of ears and stalks of maize with Fusarium moniliforme. Plant Dis. 74, 952-956. doi: 10.1094/PD-74-0952

EC (2006). Commission Recommendation of 17 August 2006 on the Presence of Deoxynivalenol, Zearalenone, Ochratoxin A, T-2 and HT-2 and Fumonisins in Products Intended for Animal Feeding.

EC (2007). Commission Regulation (EC) No 1126/2007 of 28 September 2007 Amending Regulation (EC) No 1881/2006 Setting Maximum Levels for Certain Contaminants in Foodstuffs As Regards Fusarium toxins in Maize and Maize Products.

Eller, M. S., Payne, G. A., and Holland, J. B. (2010). Selection for reduced Fusarium ear rot and fumonisin content in advanced backcross maize lines and their topcross hybrids. Crop Sci. 50, 2249-2260. doi: 10.2135/cropsci2009.1 1.0683

Elshire, R. J., Glaubitz, J. C., Sun, Q., Poland, J. A., Kawamoto, K., Buckler, E. S., et al. (2011). A robust, simple genotyping-by-sequencing (GBS) approach for high diversity species. PLoS ONE 6:e19379. doi: 10.1371/journal.pone.0019379

Gallo, A., Giuberti, G., Frisvad, J. C., Bertuzzi, T., and Nielsen, K. F. (2015). Review on mycotoxin issues in ruminants: occurrence in forages, effects of mycotoxin ingestion on health status and animal performance and practical strategies to counteract their negative effects. Toxins (Basel). 7, 3057-3111. doi: 10.3390/toxins7083057

Jardine, D. J., and Leslie, J. F. (1992). Aggressiveness of Gibberella fujikuroi (Fusarium moniliforme) isolates to grain-sorghum under greenhouse conditions. Plant Dis. 76, 897-900. doi: 10.1094/PD-76-0897

Kearse, M., Moir, R., Wilson, A., Stones-Havas, S., Cheung, M., Sturrock, S., et al. (2012). Geneious basic: an integrated and extendable desktop software platform for the organization and analysis of sequence data. Bioinformatics 28 , 1647-1649. doi: 10.1093/bioinformatics/bts199

Lanubile, A., Bernardi, J., Battilani, P., Logrieco, A., and Marocco, A. (2012). Resistant and susceptible maize genotypes activate different transcriptional responses against Fusarium verticillioides. Physiol. Mol. Plant Pathol. 77, 52-59. doi: 10.1016/j.pmpp.2011.12.002

Lanubile, A., Ferrarini, A., Maschietto, V., Delledonne, M., Marocco, A., and Bellin, D. (2014). Functional genomic analysis of constitutive and inducible defense responses to Fusarium verticillioides infection in maize genotypes with contrasting ear rot resistance. BMC Genomics 15:710. doi: $10.1186 / 1471-2164-15-710$

Lanubile, A., Maschietto, V., Borrelli, V., Stagnati, L., Logrieco, A. F., and Marocco, A. (2017). Molecular basis of resistance to Fusarium ear rot in maize. Front. Plant Sci. 8:1774. doi: 10.3389/fpls.2017.01774

Lanubile, A., Pasini, L., Lo Pinto, M., Battilani, P., Prandini, A., and Marocco, A. (2011). Evaluation of broad spectrum sources of resistance to Fusarium verticillioides and advanced maize breeding lines. World Mycotoxin J. 4, 43-51. doi: 10.3920/WMJ2010.1206 
Löffler, M., Kessel, B., Ouzunova, M., and Miedaner, T. (2010). Population parameters for resistance to Fusarium graminearum and Fusarium verticillioides ear rot among large sets of early, mid-late and late maturing European maize (Zea mays L.) inbred lines. Theor. Appl. Genet. 120, 1053-1062. doi: 10.1007/s00122-009-1233-9

Logrieco, A., Mule, G., Moretti, A., and Bottalico, A. (2002). Toxigenic Fusarium species and mycotoxins associated with maize ear rot in Europe. Eur. J. Plant Pathol. 108, 597-609. doi: 10.1023/A:1020679029993

Maiorano, A., Reyneri, A., Magni, A., and Ramponi, C. A. (2009a). Decision tool for evaluating the agronomic risk of exposure to fumonisins of different maize crop management systems in Italy. Agric. Syst. 102, 17-23. doi: 10.1016/j.agsy.2009.06.003

Maiorano, A., Reyneri, A., Sacco, D., Magni, A., and Ramponi, C. (2009b). A dynamic risk assessment model (FUMAgrain) of fumonisin synthesis by Fusarium verticillioides in maize grain in Italy. Crop Prot. 28, 243-256. doi: 10.1016/j.cropro.2008.10.012

Maschietto, V., Colombi, C., Pirona, R., Pea, G., Strozzi, F., Marocco, A., et al. (2017). QTL mapping and candidate genes for resistance to Fusarium ear rot and fumonisin contamination in maize. BMC Plant Biol. 17, 1-21. doi: 10.1186/s12870-017-0970-1

Mesterhazy, A., Lemmens, M., and Reid, L. M. (2012). Breeding for resistance to ear rots caused by Fusarium spp. in maize - a review. Plant Breed. 131, 1-19. doi: 10.1111/j.1439-0523.2011.01936.x

Mideros, S. X., Warburton, M. L., Jamann, T. M., Windham, G. L., Williams, W. P., and Nelson, R. J. (2014). Quantitative trait loci influencing mycotoxin contamination of maize: analysis by linkage mapping, characterization of near-isogenic lines, and meta-analysis. Crop Sci. 54, 127-142. doi: 10.2135/cropsci2013.04.0249

Miedaner, T., Bolduan, C., and Melchinger, A. E. (2010). Aggressiveness and mycotoxin production of eight isolates each of Fusarium graminearum and Fusarium verticillioides for ear rot on susceptible and resistant early maize inbred lines. Eur. J. Plant Pathol. 127, 113-123. doi: 10.1007/s10658-009-9576-2

Miedaner, T., Gwiazdowska, D., and Waśkiewicz, A. (2017). Editorial: management of Fusarium species and their mycotoxins in cereal food and feed. Front. Microbiol. 8:1543. doi: 10.3389/fmicb.2017.01543

Munkvold, G. P. (2003a). Cultural and genetic approaches to managing mycotoxins in maize. Ann. Rev. Phytopathol. 41, 99-116. doi: 10.1146/annurev.phyto.41.052002.095510

Munkvold, G. P. (2003b). Epidemiology of Fusarium diseases and their mycotoxins in maize ears. Eur. J. Plant Pathol. 109, 705-713. doi: 10.1023/A:1026078324268

Munkvold, G. P., and Carlton, W. M. (1997). Influence of inoculation method on systemic Fusarium moniliforme infection of maize plants grown from infected seeds. Plant Dis. 81, 211-216.

Munkvold, G. P., McGee, D. C., and Carlton, W. M. (1997). Importance of different pathways for maize kernel infection by Fusarium moniliforme. Phytopathology 87, 209-217.

Oldenburg,. E., and Ellner, F. (2005). Fusarium mycotoxins in forage maize - detection and evaluation. Mycotoxin Res. 21, 105-107. doi: 10.1007/BF02954430

Pérez-Brito, D., Jeffers, D., González-de-León, D., Khairallah, M., Cortés-Cruz, M., Velázquez-Cardelas, G., et al. (2001). QTL mapping of Fusarium moniliforme ear rot resistance in highland maize, Mexico. Agrociencia 35, 181-196.

Peterson, B. K., Weber, J. N., Kay, E. H., Fisher, H. S., and Hoekstra, H. E. (2012). Double Digest RADseq: an inexpensive method for de novo SNP discovery and genotyping in model and non-model species. PLoS ONE. 7:e37135. doi: 10.1371/journal.pone.0037135

Presello, D. A., Iglesias, J., Botta, G., and Eyhérabide, G. H. (2007). Severity of Fusarium ear rot and concentration of fumonisin in grain of Argentinian maize hybrids. Crop Prot. 26, 852-855. doi: 10.1016/j.cropro.2006.08.004

Presello, D. A., Pereyra, A. O., Iglesias, J., Fauguel, C. M., Sampietro, D. A., and Eyherabide, G. H. (2011). Responses to selection of $S_{5}$ inbreds for broad-based resistance to ear rots and grain mycotoxin contamination caused by Fusarium spp. in maize. Euphytica 178, 23-29. doi: 10.1007/s10681-010-0255-3

Presello, D. A., Reid, L. M., Butler, G., and Mather, D. E. (2005). Pedigree selection for Gibberella ear rot resistance in maize populations. Euphytica 143, 1-8. doi: 10.1007/s10681-005-6149-0

Presello, D. A., Reid, L. M., and Mather, D. E. (2004). Resistance of Argentine maize germplasm to Gibberella and Fusarium ear rots. Maydica 49, 73-81.
Reid, L. M., Woldemariam, T., Zhu, X., Stewart, D. W., and Schaafsma, A. W. (2002). Effect of inoculation time and point of entry on disease severity in Fusarium graminearum, Fusarium verticillioides, or Fusarium subglutinans inoculated maize ears. Can. J. Plant Pathol. 24, 162-167. doi: 10.1080/07060660309506991

Robertson, L. A., Kleinschmidt, C. E., White, D. G., Payne, G. A., Maragos, C. M., and Holland, J. B. (2006). Heritabilities and correlations of Fusarium ear rot resistance and fumonisin contamination resistance in two maize populations. Crop Sci. 46, 353-361. doi: 10.2135/cropsci2005.0139

Robertson-Hoyt, L. A., Jines, M. P., Balint-Kurti, P. J., Kleinschmidt, C. E., White, D. G., Payne, G. A., et al. (2006). QTL Mapping for Fusarium ear rot and fumonisin contamination resistance in two maize populations. Crop Sci. 46, 1734-1743. doi: 10.2135/cropsci2005.12-0450

Saitou, N., and Nei, M. (1987). The neighbor-joining method: a new method for reconstructing phylogenetic trees. Mol. Biol. Evol. 4, 406-425

Santiago, R., Cao, A., and Butrón, A. (2015). Genetic factors involved in fumonisin accumulation in maize kernels and their implications in maize agronomic management and breeding. Toxins (Basel). 7, 3267-3296. doi: 10.3390/toxins7083267

Santiago, R., Cao, A., Malvar, R. A., and Butron, A. (2013). Is it possible to control fumonisin contamination in maize kernels by using genotypes resistant to the mediterranean corn borer? J. Econ. Entomol. 106, 2241-2246. doi: 10.1603/EC13084

Schaafsma, A. W., Miller, J. D., Savard, M., and Ewing, R. J. (1993). Ear rot development and mycotoxin production in corn in relation to inoculation method, corn hybrid, and species of Fusarium. Can. J. Plant Pathol. 15, 185-192. doi: 10.1080/07060669309500821

Small, I. M., Flett, B. C., Marasas, W. F. O., McLeod, A., Stander, M. A., and Viljoen, A. (2012). Resistance in maize inbred lines to Fusarium verticillioides and fumonisin accumulation in South Africa. Plant Dis. 96, 881-888. doi: 10.1094/PDIS-08-11-0695

Smith, J. S. C., Duvick, D. N., Smith, O. S., Cooper, M., and Feng, L. (2004) Changes in pedigree backgrounds of pioneer brand maize hybrids widely grown from 1930 to 1999 . Crop Sci. 44, 1935-1946. doi: 10.2135/cropsci20 04.1935

Smith, S. (2007). Pedigree background changes in U.S. hybrid maize between 1980 and 2004. Crop Sci. Soc. Am. 47, 1914-1926. doi: 10.2135/cropsci2006.12.0763

Stoycho, D. S. (2015). Foodborne mycotoxicoses, risk assessment and underestimated hazard of masked mycotoxins and joint mycotoxin effects or interaction. Environ. Toxicol. Pharmacol. 39, 794-809. doi: 10.1016/j.etap.2015.01.022

Tamura, K., and Nei, M. (1993). Estimation of the number of nucleotide substitutions in the control region of mitochondrial DNA in humans and chimpanzees. Mol. Biol. Evol.10, 512-526.

Toldi, E., Bartok, T., Varga, M., Szekeres, A., Toth, B., and Mesterhazy, A. (2008). The role of breeding in reducing mycotoxin contamination in maize. Cereal Res. Commun. 36, 83-191.

Vasileiadis, V. P., Otto, S., Sattin, M., Palinkás, Z., Veres, A., Bán, R., et al. (2011). Crop protection in European maize-based cropping systems: current practices and recommendations for innovative integrated pest management. Agric. Syst. 104, 533-540. doi: 10.1016/j.agsy.2011.04.002

Venturini, G., Assante, G., and Vercesi, A. (2011). Fusarium verticillioides contamination patterns in northern Italian maize during the growing season. Phytopathol. Mediterr. 50, 110-120. doi: 10.14601/Phytopathol_Mediterr-8680

Voss, K. A., Gelineau-van Waes, J. B., and Riley, R. T. (2006). Fumonisins: current research trends in developmental toxicology. Mycotoxin Res. 22, 61-69. doi: 10.1007/BF02954559

Waśkiewicz, A., Irzykowska, L., Bocianowski, J., Karolewski, Z., Weber, Z., and Golinski, P. (2013a). Fusariotoxins in asparagus - their biosynthesis and migration. Food Add. Contam. 30, 1332-1338. doi: 10.1080/19440049.2013.796095

Waśkiewicz, A., Stepien, Ł., Wilman, K., and Kachlicki, P. (2013b). Diversity of pea-associated $F$. proliferatum and $F$. verticillioides populations revealed by FUM1 sequence analysis and fumonisin biosynthesis. Toxins 5, 488-503. doi: $10.3390 /$ toxins 5030488

Wisser, R. J., Balint-Kurti, P. J., and Nelson, R. J. (2006). The genetic architecture of disease resistance in maize: a synthesis of published studies. Phytopathology 96, 120-129. doi: 10.1094/PHYTO-96-0120 
Xiang, K., Zhang, Z. M., Reid, L. M., Zhu, X. Y., Yuan, G. S., and Pan, G. T. (2010). A meta-analysis of QTL associated with ear rot resistance in maize. Maydica 55, 281-290.

Yang, G. Q., Chen, Y.-M., Wang, J.-P., Guo, C., Zhao, L., Wang, X.-Y., et al. (2016). Development of a universal and simplified ddRAD library preparation approach for SNP discovery and genotyping in angiosperm plants. Plant Meth. 12:39. doi: 10.1186/s13007-016-0139-1

Yuan, G., Zhang, Z., Xiang, K., Shen, Y., Du, J., Lin, H., et al. (2013). Different gene expressions of resistant and susceptible maize inbreds in response to Fusarium verticillioides infection. Plant Mol. Biol. Rep. 31, 925-935. doi: 10.1007/s11105-013-0567-2

Zijlstra, C., Lund, I., Justesen, A., Nicolaisen, M., Bianciotto, V., Posta, K., et al. (2011). Combining novel monitoring tools and precision application technologies for integrated high-tech crop protection in the future (a discussion document). Pest Manag. Sci. 67, 616-625. doi: 10.1002/p s. 2134

Zila, C. T., Ogut, F., Romay, M. C., Gardner, C. A., Buckler, E. S., and Holland, J. B. (2014). Genome-wide association study of Fusarium ear rot disease in the U.S.A. maize inbred line collection. BMC Plant Biol. 14:372 doi: 10.1186/s12870-014-0372-6

Zila, C. T., Samayoa, L. F., Santiago, R., Butrón, A., and Holland, J. B. (2013). A genome-wide association study reveals genes associated with Fusarium ear rot resistance in a maize core diversity panel. G3 Genes Genomes Genet. 3, 2095-2104. doi: 10.1534/g3.113.007328

Conflict of Interest Statement: The authors declare that the research was conducted in the absence of any commercial or financial relationships that could be construed as a potential conflict of interest.

Copyright (c) 2019 Czembor, Waśkiewicz, Piechota, Puchta, Czembor and Stẹpień. This is an open-access article distributed under the terms of the Creative Commons Attribution License (CC BY). The use, distribution or reproduction in other forums is permitted, provided the original author(s) and the copyright owner(s) are credited and that the original publication in this journal is cited, in accordance with accepted academic practice. No use, distribution or reproduction is permitted which does not comply with these terms. 